\title{
Article \\ Effects of Ecological Restoration Using Non-Native Mangrove Kandelia obovata to Replace Invasive Spartina alterniflora on Intertidal Macrobenthos Community in Maoyan Island (Zhejiang, China)
}

\author{
Qiuxuan Wang ${ }^{1}$, Carlos Duarte ${ }^{2}$, Li Song ${ }^{1}$, George Christakos ${ }^{1,3}$, Susana Agusti ${ }^{2}$ and Jiaping Wu ${ }^{1, * \mathbb{C}}$ \\ 1 Ocean College, Zhejiang University, Zhoushan 316000, China; wongchooseon@163.com (Q.W.); \\ 11734036@zju.edu.cn (L.S.); pierianspring@gmail.com (G.C.) \\ 2 Red Sea Research Center, King Abdullah University of Science and Technology, Thuwal 23955, Saudi Arabia; \\ carlos.duarte@kaust.edu.sa (C.D.); susana.agusti@kaust.edu.sa (S.A.) \\ 3 Department of Geography, San Diego State University, San Diego, CA 92182, USA \\ * Correspondence: 21734012@zju.edu.cn
}

Citation: Wang, Q.; Duarte, C.; Song, L.; Christakos, G.; Agusti, S.; Wu, J. Effects of Ecological Restoration Using Non-Native Mangrove Kandelia obovata to Replace Invasive Spartina alterniflora on Intertidal Macrobenthos Community in Maoyan Island (Zhejiang, China). J. Mar. Sci. Eng. 2021, 9, 788. https://doi.org/ 10.3390/jmse9080788

Academic Editor: William

G. Ambrose

Received: 16 June 2021

Accepted: 20 July 2021

Published: 22 July 2021

Publisher's Note: MDPI stays neutral with regard to jurisdictional claims in published maps and institutional affiliations.

Copyright: (c) 2021 by the authors Licensee MDPI, Basel, Switzerland. This article is an open access article distributed under the terms and conditions of the Creative Commons Attribution (CC BY) license (https:// creativecommons.org/licenses/by/ $4.0 /)$.
Abstract: Spartina alterniflora has extensively invaded the coastline of China, including in Maoyan Island of Zhejiang Province. Ecological restoration has been conducted using non-native mangrove Kandelia obovata to replace $S$. alterniflora in an attempt to restore the impacted intertidal zones. To illustrate the ecological effectiveness of the restoration projects, macrobenthos communities were studied among different habitats within the restored areas, including one non-restored $S$. alterniflora marsh (SA) and three differently-aged restored K. obovata stands planted in 2003, 2009, and 2011 respectively (KF14, KF8, and KF6). Besides, one unvegetated mudflat (MF) adjacent to the non-restored S. alterniflora marsh and one K. obovata forest transplanted in 2006 (RKF) at a previously barren mudflat without invasion history of $S$. alterniflora were set as reference sites. A total of 69 species of macrobenthos were collected from Maoyan Island, and the species richness was dominated by gastropoda (23 species), polychaeta (18 species), and malacostraca (16 species). There was no significant difference between the six sites in terms of the abundance of macrobenthos, with the average values of abundance peaking in KF6 (734.7 ind $\mathrm{m}^{-2}$ ) and being lowest in RKF ( 341.3 ind $\mathrm{m}^{-2}$ ). The six sites had significant differences in terms of the biomass of macrobenthos. The KF8 site contained the highest average biomass $\left(168.3 \mathrm{~g} \mathrm{~m}^{-2}\right)$, whereas the MF site had the lowest $\left(54.3 \mathrm{~g} \mathrm{~m}^{-2}\right)$. The Shannon-Wiener diversity index and Pielou's evenness index of the macrobenthos did not exhibit significant differences among the six sites. However, the results of permutational multivariate analysis of variance (PERMANOVA) revealed significant spatial differences in the macrobenthos community structure between the sites. Since KF14 shared a similar macrobenthos community structure with RKF, while representing a strikingly different structure from SA, we infer that ecological restoration using $K$. obovata can restore the macrobenthos community to resemble to a normally planted K. obovata forest about 15 years after restoration.

Keywords: coastal wetland 1; Kandelia obovata 2; Spartina alterniflora invasion 3; macrobenthos community 4; mangrove restoration 5

\section{Introduction}

Biological invasion is a pervasive environmental issue globally, threating the biodiversity and functions of native ecosystems and even human well-being [1]. Coastal wetland ecosystems are fragile and are heavily infested with invasive plants around the world $[2,3]$. Spartina alterniflora is considered to be one of the most harmful invasive plants in coastal China and has caused serious ecological consequences, such as changing seascape, outcompeting native plants, and reducing local biodiversity [4]. Invasive Spartina alter the 
recipient systems by changing vegetation structure, sediment properties, and hydrological conditions, and further erode indigenous macrobenthos diversity $[5,6]$.

To address these issues, several methods have been used to control and prevent the expansion of S. alterniflora, such as burning, cutting, digging, waterflooding, and herbicide usage [7-9]. However, these traditional measures have limited effectiveness, as they are resource-demanding and $[10,11]$, in the case of herbicides, may cause chemical pollution [11]. This has led to a search for better control methods. Biological control through releasing the invasive species' natural enemy has proven to be an economical and effective method of control of widespread invasive plants. For example, the introduction of planthopper Prokelisia marginata reduced S. alterniflora biomass by 50\% and seed viability by $90 \%$ in Willapa Bay and Puget Sound (the USA) [12]. However, classical biological control methods usually have the risk of the introduced biocontrol agents having negative consequences on local ecosystems. The introduction of a biocontrol agent proceeds only after fully demonstrating its high level of host specificity and after ruling out the possibility that it could vector a disease [12]. Considering ethical concerns and legal risks of classical biological controls, these methods have not been experimented with so far in China [10].

In China, a new biocontrol method-replacement control-has obtained much attention and has been used widely. This approach is based on the rules of interspecies competition and plant community succession. It uses a more valuable species (whether native or non-native) to replace a detrimental plant species and implement the goal of ecological restoration at a higher level [13]. Replacement control seems to have advantages over conventional biocontrol methods, such as better efficacy, higher safety, and longer-lasting control [13]. However, just like the selection of conventional biocontrol agents, care is especially needed in choosing exotic replacement species, which must be proved to be non-harmful to native species and non-invasive to native ecosystems after long-term growth.

Mangrove Kandelia obovata has been shown to inhibit S. alterniflora [14,15]. It is a cold-resistant eurytopic species and distributes in all of the coastal provinces of native mangroves distribution, with its northern boundary extending to $\sim 27^{\circ} 20^{\prime} \mathrm{N}$ (the northernmost distribution of China's natural mangroves) [16,17]. This species was originally introduced in 1957 to Ximen Island in Zhejiang Province $\left(\sim 28^{\circ} 20^{\prime} \mathrm{N}\right)$ for mangrove restoration from Fuqing County in Fujian Province $\left(\sim 25^{\circ} 41^{\prime} \mathrm{N}\right)$; before that, there were no mangroves in Zhejiang [18]. After several decades of restoration, owing to high tolerance to low temperature, K. obovata forests have been successfully established in many regions, currently covering a total area of around 400 ha in Zhejiang. Because low temperature stress can strongly inhibit the natural reproductive capacity of $K$. obovata, which often inhibits the development of the K. obovata community, K. obovata exhibits no invasiveness 60 years after its introduction to Ximen Island. In addition, contrary to the notorious S. alterniflora, K. obovata has provided great ecological and economic benefits to native ecosystems and the local community [19]. Thus, the proper physiological characteristics and high service values of K. obovata enable it to be the best ecological restoration species in Zhejiang [19].

To illustrate the effectiveness of ecological restoration, it is necessary to conduct research on macrobenthos communities in the coastal areas that have been flagged for restoration. Macrobenthos communities are ubiquitous and functionally important components in coastal wetlands. These organisms play key ecological roles in shaping the structure and function of ecosystem through their engineering activities, such as burrow construction and maintenance, seed burial, propagule predation, and litter processing [20-22]. Macrobenthos communities are accepted as valid indicators for changes in functions and ecological status of coastal ecosystems [23], owing to the fact that macrobenthos are not only of unique biological characteristics (e.g., sedentary life-style, long life span, species-specific response to environmental stresses), but also can respond rapidly to both natural and anthropogenic stresses [24].

A previous study has been conducted to show the effects of replacing S. alterniflora with native K. obovata on macrobenthos communities in Dazhou Island (Fujian) [14]. The 
plantation of K. obovata after S. alterniflora was eliminated successfully inhibited the spread of S. alterniflora and also restored the typical benthic food wed of mature mangrove ecosystems [14]. In Zhejiang, some such studies have been conducted on those restoration projects using non-native K. obovata. In the Shupaisha wetland, 2-year-old K. obovata forests which were established in areas previously occupied by S. alterniflora exhibited much higher diversity of macrobenthos communities than non-restored S. alterniflora marshes [25]. In the Aojiang Estuary, almost no S. alterniflora individuals were found in the 3-year-old K. obovata plantation, whereas lower macrobenthos diversity was observed in the K. obovata plantation relative to $S$. alterniflora marsh [26].

Here we explore the changes in macrobenthos communities during the S. alterniflora invasion and the subsequent restoration adopting non-native K. obovata in Maoyan Island (Zhejiang, China). Specifically, we: (1) compare the impacts of non-indigenous K. obovata and S. alterniflora on the macrobenthos communities; (2) elucidate if the use of non-native K. obovata for the replacement of invasive S. alterniflora can result in the restoration of the macrobenthos communities; and (3) apply macrobenthos as indicators to assess the benthic ecological status of associated habitats.

\section{Materials and Methods}

\subsection{Study Area}

This study was carried out on Maoyan Island, Zhejiang, China (Figure 1). Maoyan Island is located in the inner part of Yueqing Bay. This island covers a land area of $4.74 \mathrm{~km}^{2}$ and a mudflat area of $2.45 \mathrm{~km}^{2}$, which makes it the second biggest island in Yueqing Bay. This region has a subtropical marine monsoon climate. According to the data from the local meteorological station, the perennial mean air temperature of this region is $17.1^{\circ} \mathrm{C}$, the perennial mean precipitation of this region is $1460.3 \mathrm{~mm}$, and the perennial mean sunshine is $1850.5 \mathrm{~h}$. It experiences a semidiurnal tide with an average range of $5.15 \mathrm{~m}$ and a maximal range of $8.34 \mathrm{~m}$ (http:/ / www.yuhuan.gov.cn/ accessed on 21 July 2021).
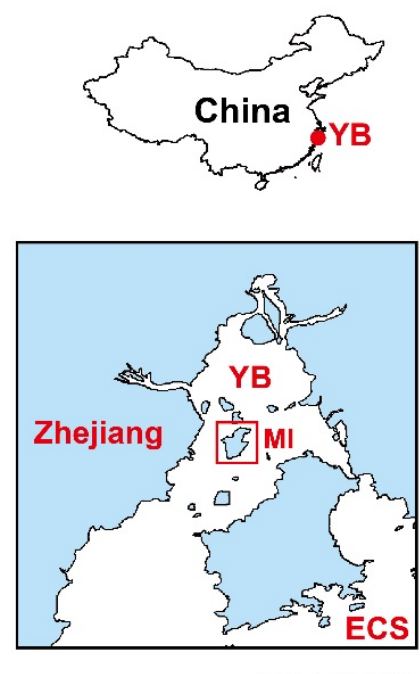

$28^{\circ} 11^{\prime} 12^{\prime \prime} \mathrm{N}$
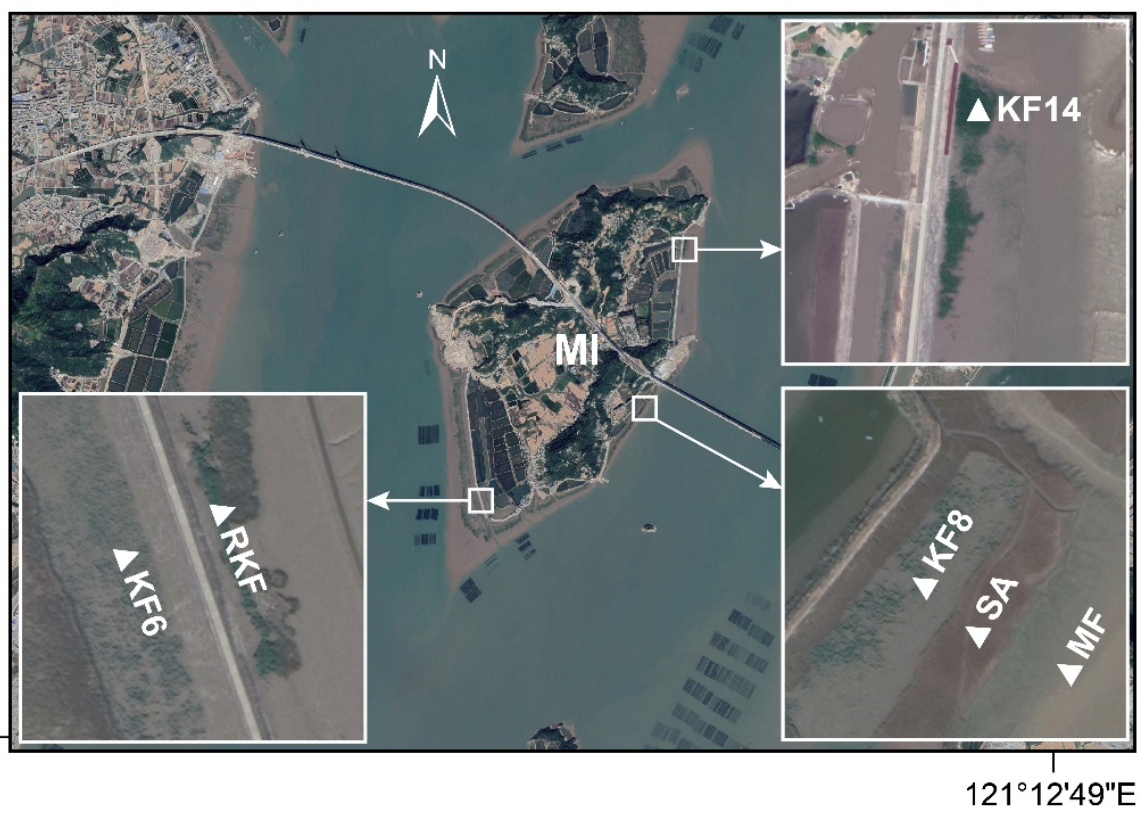

Figure 1. Location of Maoyan Island and the sampling sites. YB: Yueqing Bay, ECS: East China Sea, MI: Maoyan Island. MF: unvegetated mudflat, SA: S. alterniflora marsh, KF6: 6-year-old restored K. obovata forest, KF8: 8-year-old restored K. obovata forest, KF14: 14-year-old restored K. obovata forest, RKF: 11-year-old reference K. obovata forest.

S. alterniflora expanded to Maoyan Island in 1996, following its earlier introduction to Zhejiang with the objectives of tidal land reclamation and wetland restoration in 1983. The rampant spread of S. alterniflora to the coast has since ensued, with the majority of 
the intertidal mudflat occupied by this invader. For the sake of S. alterniflora control and ecological restoration, local residents and government have planted $K$. obovata over the years since 2003, resulting in an estimated K. obovata area of about 100 ha on Maoyan Island at present. Most such plantations were conducted in areas previously colonized by S. alterniflora, with the removal of $S$. alterniflora conducted prior to restoration, while there are also some $K$. obovata forests being planted in previously unvegetated areas. All of the projects were reviewed and approved by the People's Government of Zhejiang Province, and carried out under the current law of the People's Republic of China.

In the areas of $K$. obovata restoration after S. alterniflora elimination, one non-restored S. alterniflora marsh (SA) and three differently-aged restored K. obovata stands planted in 2003 (KF14), 2009 (KF8), and 2011 (KF6) respectively, were selected. One unvegetated mudflat (MF) adjacent to the non-restored S. alterniflora marsh, and one reference K. obovata forest (RKF) transplanted in 2006 at a previously barren mudflat without invasion history of S. alterniflora, were selected as references to assess the effects of S. alterniflora invasion and mangrove restoration on the macrobenthos communities.

\subsection{Macrobenthos Sampling and Laboratory Procedures}

Seasonal samplings of macrobenthos at each of the above sites were undertaken in October 2018, December 2018, March 2019, and July 2019 to represent the autumn, winter, spring, and summer seasons, respectively. At each sampling time and site, triplicate sediment samples of $25 \mathrm{~cm} \times 25 \mathrm{~cm} \times 30 \mathrm{~cm}$ were randomly collected. A metal frame of the designated volume was pushed down into sediment prior to shoveling. The sediment samples collected were then sieved by a $0.5 \mathrm{~mm}$ mesh to retrieve the macrobenthos. All the macrobenthos specimens were preserved in $5 \%$ formalin, and the organisms were identified at the lowest taxonomic level possible under the Stemi508 (ZEISS), and then were counted and weighed (fresh weights) to the nearest 0.0001 on a precision electronic laboratory balance.

\subsection{Data Analyses}

Data analysis was based on an appropriate synthesis of statistical techniques. For each sample, the Shannon-Wiener diversity index $\left(H^{\prime},(\log 2)\right)$, Pielou's evenness index $(J)$, total abundance, and total biomass were calculated and the different significance among the sampling seasons and sampling sites were tested using the two-way ANOVA statistical technique. For the macrobenthos community featured in this study, the four groups, including gastropoda, polychaeta, malacostraca, and phascolosomatidea, were relatively important, because together they accounted for $89.14 \%$ of the total abundance and $93.16 \%$ of the total biomass. Therefore, the abundance and biomass of each important group were also examined using the two-way ANOVA. The Tukey HSD method was then applied for pairwise comparisons if any significant differences were found in the ANOVA test. The dominant species for each site were determined by the relative importance index (IRI):

$$
I R I=(N+W) \times F
$$

where $N$ is the abundance percent of the species; $W$ is the biomass percent of the species; $F$ is the frequency of occurrence percentage of the species [27]. A species with IRI $>750$ would be considered to be the dominant species. The calculations and statistical analyses were conducted using the software Excel 2019 and MATLAB 2019b.

Multivariate analyses were performed using PRIMER 7.0. The seasonal and spatial variations in the macrobenthos community structure were explored using principal coordinates scaling ordination (PCO) analysis and hierarchical agglomerative clustering analysis with the group-average linking method. The significantly different groups of the cluster analysis were detected using the similarity profile (SIMPROF) test. The Bray-Curtis similarity matrices were constructed based on the square root transformed abundance data before the analyses. In order to reduce the impacts of rare species, species that contributed less than $1 \%$ of the total abundance were eliminated, and then species that accounted for 
more than 3\% abundance of each sample were included again. A permutational multivariate analysis of variance (PERMANOVA) with "season" and "site" as fixed factors was employed to assess the statistical significance of differences between sampling seasons and sampling sites [28,29].

AZTI's Marine Biotic Index (AMBI) and its multivariate extension (M-AMBI) were applied to assess the benthic ecological status of the study area, using the software v6.0 available on AZTI's web page (https: / / www.azti.es / accessed on 21 July 2021) with the updated species list of December 2020 [24,30,31]. The boundaries of AMBI and M-AMBI were used to define five ecological quality status classifications (high/undisturbed, good/slightly disturbed, moderate/meanly disturbed, poor/heavily disturbed, bad/extremely disturbed) according to Luo et al. (2014) [32].

\section{Results}

\subsection{Species Composition and Biodiversity}

Over the four seasons considered, a total of 69 macrobenthos species were identified. Gastropoda (33.3\%, 23 species), polychaeta (26.1\%, 18 species), and malacostraca $(23.2 \%, 16$ species) dominated the community species richness, followed by bivalvia $(8.7 \%$, 6 species), actinopterygii (2.9\%, 2 species), phascolosomatidea (1.4\%, 1 species), anthozoa (1.4\%, 1 species), thecostraca (1.4\%, 1 species), and nemertea (1.4\%, 1 species).

The implementation of the two-way ANOVA revealed that the sampling season only significantly influenced the malacostracans biomass and total biomass (all $p<0.05)$. In contrast, the sampling site significantly affected the total biomass, the abundance of all of the four important groups, and the biomass of gastropods, malacostracans, and phascolosomatids (all $p<0.05$ ). The interaction between season and site did not significantly affect the abundance and the biomass of any taxonomic group or the whole community $(p>0.05)$. The abundance and biomass data during all seasons could therefore be pooled together to analyze spatial differences between sites. The results of LSD's post-hoc tests for these analyses are shown in Figure 2. Compared with the mudflat, S. alterniflora and 6- and 8-year-old K. obovata forests obviously increased the abundance and biomass of gastropods, but the 14-year-old K. obovata forests and the reference $K$. obovata forest largely decreased the abundance of gastropods relative to the mudflat. The malacostracans abundance in the 6-year-old K. obovata forest was significantly higher than that of all other sites, while the 6- and 8-year-old K. obovata forests and reference K. obovata forest had much higher malacostracans biomass than all other sites. The 14-year-old K. obovata forest and the reference K. obovata forest demonstrated significantly higher abundance and biomass of phascolosomatids in comparison to all other habitats. The polychaetes abundance was significantly higher at the mudflat, when compared to all vegetated habitats.

The two-way ANOVA indicated that the season significantly affected the $H^{\prime}$ of macrobenthos $(p<0.05)$. However, neither $H^{\prime}$ nor $J$ was significantly affected by the site and the interaction between season and site $(p>0.05)$, so we pooled the data from different sites for further analyses. The results of LSD's post-hoc tests showed that the $H^{\prime}$ value of macrobenthos was significantly higher in the summer than that of all the other seasons (Figure 3). 

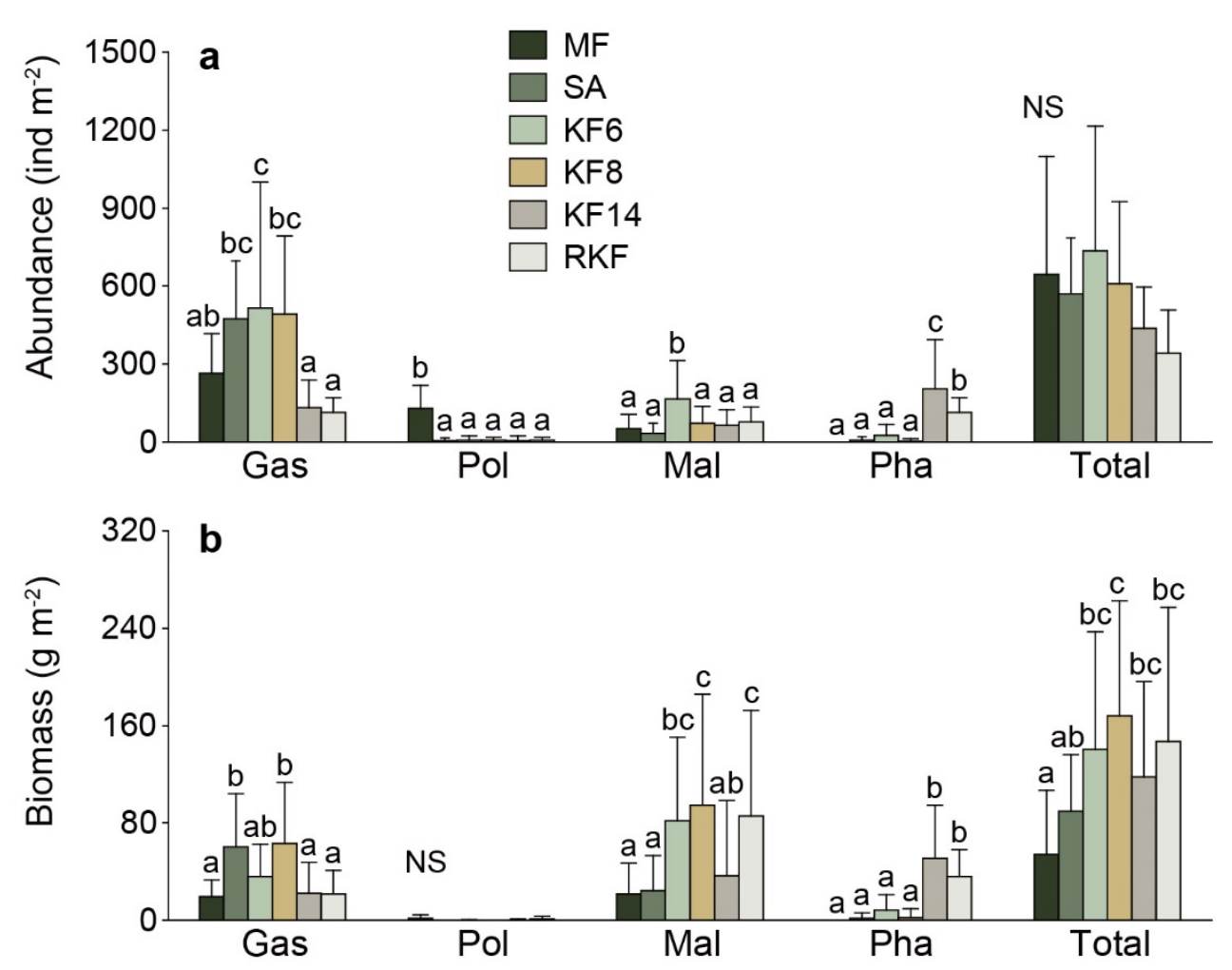

Figure 2. Abundance (Figure 2a) and biomass (Figure 2b) of the macrobenthos community at each site. Data in each site were pooled across four seasons. The letters above bars $(a, b, c)$ indicate significant differences between sites $(p<0.05)$, NS indicates no significant. Gas: Gastropoda, Mal: Malacostraca, Pha: Phascolosomatidea, Pol: Polychaeta. MF: unvegetated mudflat, SA: S. alterniflora marsh, KF6: 6-year-old restored K. obovata forest, KF8: 8-year-old restored K. obovata forest, KF14: 14-year-old restored K. obovata forest, RKF: 11-year-old reference K. obovata forest.

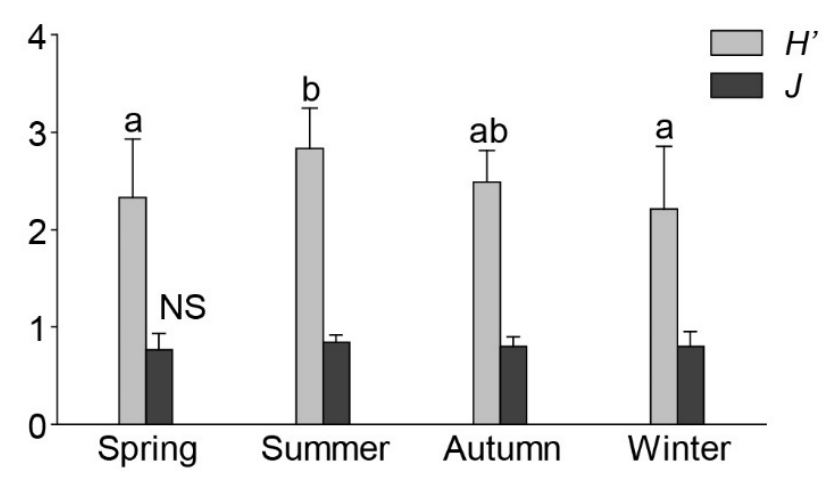

Figure 3. Shannon-Wiener diversity index $\left(H^{\prime}\right)$ and Pielous's evenness index $(J)$ of the macrobenthos community at each season. Data in each season were pooled across six sites. The letters above bars (a and b) indicate differences between seasons $(p<0.05)$, NS indicates no significant.

The species with the top three highest IRI values of the macrobenthos community are shown in Table 1. The IRI values of the species changed strongly among the sites, indicating a considerable difference in the macrobenthos community. For example, the highest dominance of Optediceros breviculum was in the mudflat, S. alterniflora marsh, and 6- and 8-year-old K. obovata forests, compared to a distinct dominance of Phascolosomatids in 14-year-old K. obovata forest and reference K. obovata forest. Tubuca arcuata was found to be a dominant species in the 6-year-old K. obovata forests and reference K. obovata forest, while this species was not dominant at other sites. 
Table 1. Species with high IRI values of the macrobenthos community at each site. $\mathrm{N}$ is the abundance percentage of the species; $\mathrm{W}$ is the biomass percentage of the species. Gray cells are species considered to be a dominant species (with IRI > 750).

\begin{tabular}{|c|c|c|c|c|c|c|c|c|c|c|c|c|c|c|c|c|c|c|}
\hline \multirow[t]{2}{*}{ Species } & \multicolumn{3}{|c|}{ MF } & \multicolumn{3}{|c|}{ SA } & \multicolumn{3}{|c|}{ KF6 } & \multicolumn{3}{|c|}{ KF8 } & \multicolumn{3}{|c|}{ KF14 } & \multicolumn{3}{|c|}{ RKF } \\
\hline & $\mathbf{N}$ & $\mathbf{W}$ & $I R I$ & $\mathbf{N}$ & $\mathbf{W}$ & $I R I$ & $\mathbf{N}$ & $\mathbf{W}$ & $I R I$ & $\mathbf{N}$ & $\mathbf{W}$ & $I R I$ & $\mathbf{N}$ & $\mathbf{W}$ & $I R I$ & $\mathbf{N}$ & W & $I R I$ \\
\hline $\mathrm{Cl}$ & 0.8 & 2.9 & 31.3 & 8.4 & 17.3 & 714.8 & 5.6 & 1.4 & 155.1 & 14.0 & 13.0 & 825.9 & 5.8 & 7.2 & 323.7 & 7.0 & 5.4 & 241.3 \\
\hline$M l$ & 9.5 & 0.8 & 258.4 & 27.1 & 2.2 & 896.4 & 4.2 & 0.3 & 87.9 & 10.3 & 0.3 & 265.3 & 1.5 & 0.1 & 22.1 & 1.6 & 0.0 & 13.2 \\
\hline $\mathrm{Ob}$ & 23.3 & 19.9 & 841.2 & 26.6 & 11.5 & 1271.5 & 36.3 & 3.9 & 1340.7 & 35.0 & 9.2 & 1349.4 & 14.9 & 4.3 & 479.9 & 10.5 & 1.4 & 265.8 \\
\hline $\mathrm{Ta}$ & 1.4 & 17.1 & 308.6 & 0.5 & 7.7 & 45.5 & 6.2 & 28.9 & 876.9 & 6.3 & 33.8 & 668.5 & 3.6 & 12.5 & 224.0 & 6.6 & 23.4 & 750.2 \\
\hline $\mathrm{Pa}$ & 0 & 0 & 0 & 1.2 & 1.8 & 25.1 & 3.4 & 5.9 & 129.2 & 0.4 & 1.3 & 4.9 & 46.5 & 42.9 & 2733.3 & 33.6 & 24.5 & 1775.8 \\
\hline
\end{tabular}

$\mathrm{Cl}$ : Cerithideopsis largillierti; Ml: Mainwaringia leithii; $\mathrm{Ob}$ : Optediceros breviculum; Ta: Tubuca arcuata; Pa: Phascolosoma arcuatum. MF: unvegetated mudflat, SA: S. alterniflora marsh, KF6: 6-year-old restored K. obovata forest, KF8: 8-year-old restored K. obovata forest, KF14: 14-year-old restored K. obovata forest, RKF: 11-year-old reference K. obovata forest.

\subsection{Macrobenthos Community Structure}

The cluster and PCO analyses visualized the seasonal and spatial variation in the macrobenthos community structure. Cluster analysis showed considerable differences between sites and the SIMPROF test identified three significant groups (significance level: $5 \%$ ) based on the sites. Group A was composed of samples from the mudflat; group B was composed of samples from the 6- and 8-year-old K. obovata forests and S. alterniflora marsh; and group $C$ was composed of samples from the 14-year-old $K$. obovata forest and reference K. obovata forest (Figure 4a). The results of PCO testing for spatial variation were consistent with those of the cluster analysis (Figure $4 \mathrm{~b}$ ). Three parts were mainly separated in the PCO plot, and each part was composed of samples that were classified into the same significant group during the cluster analysis. The first two axes of PCO explained $46.3 \%$ of the total variation. Seasonal variation was not visually identifiable in both cluster and PCO plots (Figure $4 \mathrm{a}, \mathrm{c}$ ).

The main test of PERMANOVA analysis revealed significant seasonal and spatial variability in the macrobenthos community structure (Table 2a). Season and site significantly affected the macrobenthos community $(p<0.05)$, but the interaction between the two factors had no significant effects $(p>0.05)$. Pairwise comparisons showed that significant differences existed in all pairwise combinations of seasons and sites except between the summer seasons, between autumn and winter, and between the of 14-year-old K. obovata forest site and the reference K. obovata forest site (Table $2 b, c$ ). 

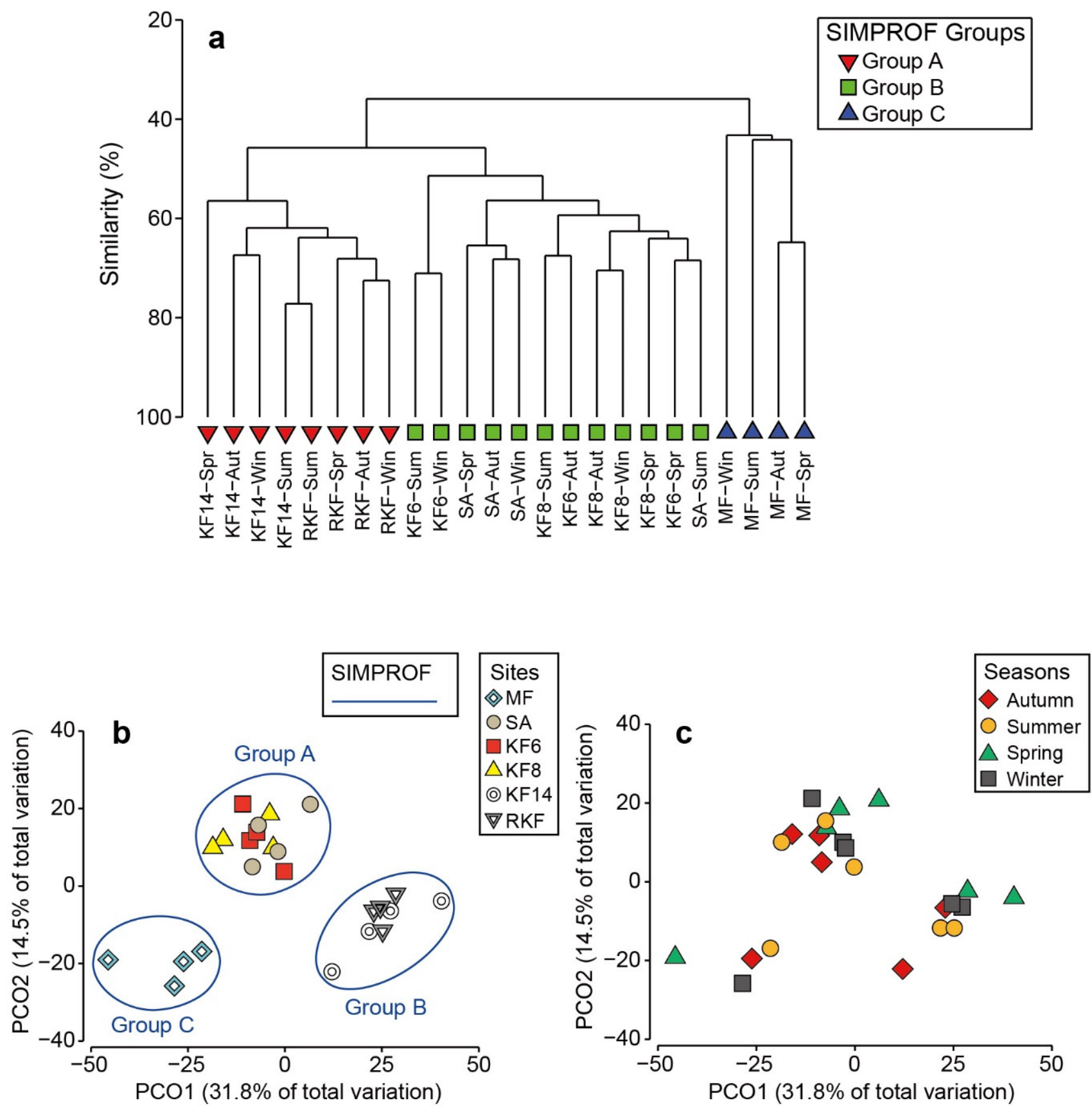

Figure 4. Cluster analysis and SIMPROF test (a) and PCO analysis for spatial (b) and seasonal (c) variations in the macrobenthos community structure. Spr: spring, Sum: summer, Aut: autumn, Win: winter. MF: unvegetated mudflat, SA: S. alterniflora marsh, KF6: 6-year-old restored K. obovata forest, KF8: 8-year-old restored K. obovata forest, KF14: 14-year-old restored K. obovata forest, RKF: 11-year-old reference K. obovata forest. 
Table 2. The test of PERMANOVA. (a) The main test of PERMANOVA analysis with "season" and "site" as fixed factors. (b) Pairwise comparisons between pairwise combinations of seasons. (c) Pairwise comparisons between pairwise combinations of sites.

\begin{tabular}{|c|c|c|c|c|c|c|}
\hline \multicolumn{7}{|c|}{ (a) } \\
\hline Source & df & SS & MS & $\begin{array}{c}\text { Pseudo- } \\
F\end{array}$ & $P($ perm $)$ & U. perms \\
\hline Sites & 5 & 50,824 & 10,165 & 5.7172 & 0.001 & 999 \\
\hline Seasons & 3 & 10,396 & 3465.5 & 1.9492 & 0.001 & 998 \\
\hline Sites $\times$ Seasons & 15 & 28,458 & 1897.2 & 1.0671 & 0.302 & 998 \\
\hline Res & 48 & 85,341 & 1777.9 & & & \\
\hline Total & 71 & $1.75 \times 10^{5}$ & & & & \\
\hline \multicolumn{7}{|c|}{ (b) } \\
\hline Seasons & Spring & Summer & Autumn & Winter & & \\
\hline Spring & $28.38 \%$ & 0.001 & 0.004 & 0.046 & & \\
\hline Summer & $68.62 \%$ & $37.74 \%$ & 0.022 & 0.091 & & \\
\hline Autumn & $69.87 \%$ & $64.38 \%$ & $35.16 \%$ & 0.428 & & \\
\hline Winter & $73.11 \%$ & $68.48 \%$ & $68.64 \%$ & $27.14 \%$ & & \\
\hline
\end{tabular}

Values on the diagonal are percent similarity within season (PERMANOVA analysis); values below the diagonal are percent dissimilarity between seasons (PERMANOVA analysis).

\begin{tabular}{ccccccc}
\hline \multicolumn{7}{c}{ (c) } \\
$\begin{array}{c}\text { Sites/ } \\
\text { Habitats }\end{array}$ & MF & SA & KF6 & KF8 & KF14 & RKF \\
\hline MF & $28.52 \%$ & 0.001 & 0.001 & 0.001 & 0.001 & 0.001 \\
SA & $73.05 \%$ & $46.30 \%$ & 0.001 & 0.037 & 0.002 & 0.001 \\
KF6 & $74.21 \%$ & $61.61 \%$ & $46.61 \%$ & 0.002 & 0.001 & 0.001 \\
KF8 & $73.62 \%$ & $58.11 \%$ & $62.78 \%$ & $41.56 \%$ & 0.001 & 0.001 \\
KF14 & $83.14 \%$ & $69.05 \%$ & $69.81 \%$ & $70.95 \%$ & $38.71 \%$ & 0.247 \\
RKF & $83.85 \%$ & $72.57 \%$ & $67.79 \%$ & $79.18 \%$ & $60.68 \%$ & $41.31 \%$ \\
\hline
\end{tabular}

Values on the diagonal are percentage of similarity within habitat (PERMANOVA analysis); values below the diagonal are percent dissimilarity between habitats (PERMANOVA analysis). MF: unvegetated mudflat, SA: S. alterniflora marsh, KF6: 6-year-old restored K. obovata forest, KF8: 8-year-old restored K. obovata forest, KF14: 14-year-old restored K. obovata forest, RKF: 11-year-old reference $K$. obovata forest.

\section{3. $A M B I$ and $M-A M B I$}

In the mudflat, S. alterniflora marsh, and 6- and 8-year-old K. obovata forests, the interpretations of ecological status were globally consistent between the AMBI and M-AMBI and classified all samples as having "good" quality status during the four seasons, except that the ecological status of S. alterniflora marsh in the spring and the 8-year-old K. obovata forest in the winter as assessed by the AMBI was "high", and that of the 6-year-old K. obovata forest in the summer was also "high", as assessed by the M-AMBI (Figure 5a,b). These results meant that the benthic environment of these four sites suffered slight disturbance.

However, in the case of the 14-year-old K. obovata forest and reference K. obovata forest, the interpretations of the ecological status provided by AMBI and M-AMBI were different, with the relative overestimation of AMBI. According to AMBI, the ecological status of the two sites was "high" during the four seasons, while based on M-AMBI, the status conditions were "good" (Figure 5a,b). 

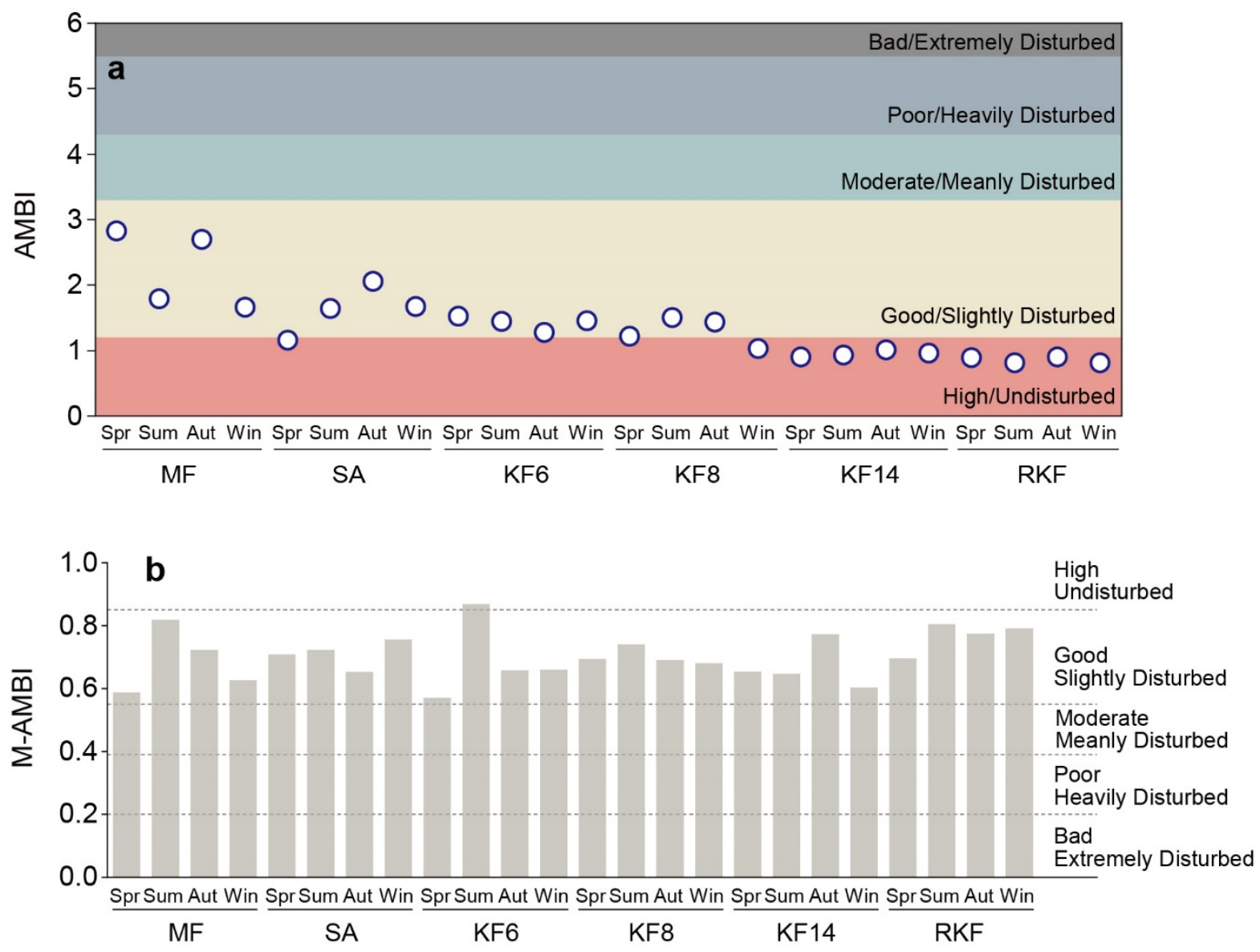

Figure 5. The value of AMBI (a) and M-AMBI (b) in each site. Spr: spring, Sum: summer, Aut: autumn, Win: winter. MF: unvegetated mudflat, SA: S. alterniflora marsh, KF6: 6-year-old restored K. obovata forest, KF8: 8-year-old restored K. obovata forest, KF14: 14-year-old restored K. obovata forest, RKF: 11-year-old reference K. obovata forest.

\section{Discussion}

\subsection{Seasonality in Macrobenthos Community}

Seasonality exerted a strong influence on the biodiversity of the macrobenthos communities in Maoyan Island, where the diversity $\left(H^{\prime}\right)$ of the macrobenthos community was highest during the summer, coinciding with a higher rainfall intensity. Salinity acts as a limiting factor in the distribution of intertidal organisms [33]. In the Yueqing Bay (characterized by a subtropical monsoon climate), the rainfall usually peaks during the summer and concurrently reduces the sediment and surface water salinity, which is conducive to diversifying macrobenthos communities [34].

\subsection{Influence of Non-Indigenous Mangrove and Spartina on Macrobenthos Communities}

Changes in vegetation structure and sediment characteristics of coastal wetlands, in association with the colonization of alien plants, may have cascading influences on the species composition and occurrence pattern of native macrobenthos communities. Our results support the correctness of previous generalizations; three distinct macrobenthos assemblages based on community structure and dominant species were distinguished between the mudflat and S. alterniflora marsh and reference K. obovata forest, indicating whether the invasion of Spartina or the plantation of non-native mangrove species intensively affected the intertidal macrobenthos communities in Maoyan Island.

Compared to the mudflat and reference K. obovata forest, gastropods inhabiting the S. alterniflora marsh had markedly higher abundance and biomass, with gastropods $O$. breviculum and $M$. leithii being the dominant species in the S. alterniflora marsh, demon- 
strating that it is a more hospitable habitat for gastropods than the other two sites. Compared with unvegetated mudflat, the facilitative roles of Spartina marsh on the development of epifaunal gastropods are related to the vegetation structures, contributing habitat complexity [35], increasing food availability [36], creating cooler and wetter conditions [35], and acting as shelters that protect gastropods against predators and baffle currents and waves away from gastropods [37]. Although mangrove trees appear to function similarly to $S$. alterniflora plants, the S. alterniflora leaves seem to be more palatable for macrobenthos than that of mangroves, because of lower concentrations of tannin and phenol, combined with higher nutritional quality (lower C/N ratio) [38].

The variations in polychaetes assemblage among different habitats were very different than those for gastropods. Both invasive S. alterniflora and planted K. obovata decreased the abundance of polychaetes in comparison to mudflat to an extreme degree. This result differed from existing paradigms regarding the positive effects of vegetation on polychaetes $[39,40]$. However, tidal level is another determinant for polychaetes distribution on intertidal zones [40]. The lower tidal sediment is moister and looser than upper tidal zone as a result of lengthened periods of submergence, facilitating populations of intertidal polychaetes [41]. Importantly, the zones with more frequent inundation have a greater potential for polychaetes larvae to receive and survive, and consequently the recruitment of polychaetes [41]. Thus, the scarcity of polychaetes in the two vegetated habitats might be attributed to the higher tidal level despite the presence of vegetation.

In contrast to the mudflat and S. alterniflora marsh, malacostracans showed a significantly higher biomass in the reference K. obovata forest, where the much higher dominance of a burrower crab T. arcuata was observed. A complex burrow is of great importance for these intertidal crabs to live, because animal burrows function as cooling space and a water reservoir for intertidal organisms [42], reducing the threat of high temperatures and desiccation. Within coastal wetlands, mangrove roots with intermediate density offer construction units for crab burrows and encourage crabs to build more complicated borrows, and in turn the over-dense root systems of S. alterniflora may impede the burrowing activities of crabs severely [43]. The reference $K$. obovata forest had a providential density of root systems, encouraging crab colonization.

The mangrove habitat has a low degree of environmental profitableness, due to the poor nutritive value of the mangrove organic matter, sediment hypersalinity and hypoxia [21], and high concentrations of tannins [44]. Therefore, species that are able to endure these environmental conditions, such as $p$. arcuatum (the sole species in the Phascolosomatidea group in our study), may dominate mangrove macrobenthos assemblages [21]. This species is a typical osmoconformer that has a great tolerance to environmental stresses. With a mud-filled gut as buffer, it can maintain a stable osmosis state against external salinity changes [45]. In addition, p. arcuatum can detoxify sulfide in anaerobic conditions [46], and synthesize polyunsaturated fatty acids from simpler precursors [47]. Such unique physiological functions may explain the presently observed preponderance of $p$. arcuatum in reference K. obovata forest.

\subsection{Influence of Mangrove Restoration on Macrobenthos Communities}

Mangrove forests in different successional stages usually support different macrobenthos communities. During the restoration process, changes to local vegetation greatly affect the shade condition, organic matter input, and physical structure of mangrove habitat, which are key factors influencing macrobenthos organisms [48,49]. It follows that macrobenthos communities are likely to change with forest development following mangrove restoration.

In this study, mangrove forests had positive impacts on gastropods assemblage during the early stages of restoration. Notably, we found a higher abundance of gastropods inhabiting 6- and 8-year-old K. obovata forests, relative to those inhabiting the mudflat. Gastropod O. breviculum, which was the most dominant species of all in the mudflat, S. alterniflora marsh, and 6- and 8-year-old K. obovata forests, had increased dominance in 
the two mangrove stands. Mangrove habitats are believed to provide similarly attractive living conditions to gastropods as the Spartina marsh does [50,51]. However, 14-year-old K. obovata forest had much lower abundance and dominance of gastropods compared to the younger ones. Mangrove gastropods are efficient consumers of benthic microalgae (e.g., microphytobenthos and phytoplankton) [50,52], suggesting that their distribution and abundance are largely determined by the availability of microalgae in surface sediment. The younger K. obovata forests had more open flats, perhaps leading to more sufficient light penetration for active growth of microalgae [53] and therefore larger abundance of gastropods; in contrast, the old K. obovata forest with denser canopy might be less suitable for algal growth [48].

In the present study, mangrove restoration appeared to have considerable effects on the spatial distribution of the malacostracans assemblage. T. arcuata was the most common malacostracan species throughout the entire sampling period. Significant difference in dominance of this crab was observed among the restored $K$. obovata forests, with high dominance in 6-year-old stand, probably because the semi-open habitat with moderate light penetration is known to favor T. arcuata [23]. Moreover, since fiddler crabs usually communicate by visual signaling or waving and the vegetation structure of mangroves may hinder visibility [54-56], these crabs may tend to avoid the old K. obovata forests with more complex structures.

During the restoration of $K$. obovata forests, $p$. arcuatum was found with distinct dominance in the 14-year-old stand, but it was not yet dominant in the 6- and 8-year-old stands. It could be inferred that $p$. arcuatum developed with the maturity of restored mangrove forest. p. arcuatum is greatly responsive to the contents of soil organic matter, which is one of the important food sources of this species [54]. Younger mangroves are not capable of producing adequate organic matter in the soil due to the low productivity [57], and these mangroves with undeveloped root systems cannot trap the same amount of fallen detritus as old mangroves retain [58].

\subsection{Assessment of the Ecological Effectiveness of Replacement Control}

The replacement of invasive $S$. alterniflora with non-native mangrove species has been proved to be feasible and effective in controlling the spread of S. alterniflora while restoring mangrove wetlands, and it is shown to have more advantages (e.g., saving time and money, having higher safety and avoiding pollution, longer-lasting control) than other control measures $[13,59]$. In our study area, it was observed that S. alterniflora has almost completely retreated from K. obovata communities, though it has still occupied the fringes of $K$. obovata plantations. The efforts made in replacement control have basically met the goals of achieving $S$. alterniflora control and mangrove restoration.

For successful restoration, it is critical to establish an ecosystem with similar ecological functions to the undegraded ones. The community structure of macrobenthos offers an insight through which to reflect the functionality and status of mangrove forest $[23,60]$. Our multivariate analyses showed that the macrobenthos community composition differed between habitats of different restoration histories, with the divergence in community structure between the non-restored S. alterniflora marsh and restored mangrove stands increasing with mangrove stand age, to be substantially different for the stand stored 14 years ago. In addition, macrobenthos assemblages of the 14-year-old restored mangrove forest and reference planted mangrove forest showed a remarkable degree of similarity, particularly in respect of the specific dominance of $p$. arcuatum; whereas 6- and 8-year-old stands possessed distinct macrobenthos community structure from the reference forest. It is logical to conclude that at Maoyan Island, even though the process may take over a decade, the ecological restoration using non-native mangrove species in habitats previously altered by invasive Spartina can result in the gradual creation of mangrove ecosystem functions, when consider macrobenthos development. Nevertheless, additional research is needed to determine whether these restored mangroves can become a provider of ecosystem functions and services resemble to nature mangrove forests (and if they can, for how long). 


\subsection{Assessment of Benthic Ecological Status}

AMBI and M-AMBI have been proven to be ecologically powerful to assess the impact of anthropogenic pressures on marine ecosystem quality [30]. In general, the mudflat, S. alterniflora marsh, and 6- and 8-year-old K. obovata forests were found to be slightly disturbed (had good ecological status) based on both AMBI and M-AMBI. The exploitation of these sites for capturing economic species (e.g., mud crabs, peanut worms, mudskippers, and octopus) could be responsible for this situation. During the course of the year, such activities by local fishermen through digging holes and setting cages on muddy substrates were taking place everywhere.

Low values of AMBI implied superior benthic ecological status of 14 years K. obovata forest and reference K. obovata forest to those of other sites. Mangrove transplantation of restored wetland has demonstrated an improvement in benthic quality status when compared to non-restored S. alterniflora and mudflat [61]. Moreover, the two older mangrove stands are included in the government conservation area, where fishing activities are forbidden and thereby human-induced disturbances are less. However, the assessment of M-AMBI was relatively underrated compared to the findings by AMBI in the two sites. It could be ascribed to the fact that AMBI tends to overestimate the benthic quality when a single species was too abundant in the macrobenthos community [32], just like the fact that $p$. arcuatum dominated the 14-year-old K. obovata forest and reference K. obovata forest in this study.

\section{Conclusions}

Our results demonstrated: (a) some striking dissimilarities among macrobenthos communities in the two non-indigenous vegetated types and in pristine mudflat; and (b) the succession of the macrobenthos communities driven by the ecological restoration of invasive S. alterniflora using K. obovata. When investigated 14 years after restoration, the macrobenthos community was found to have a disparate structure from the non-restored S. alterniflora marsh and achieved a similar community structure as that of an 11-year-old planted K. obovata forest. Accordingly, we conclude that the macrobenthos community structure can be significantly altered by S. alterniflora invasion and K. obovata plantation; and the macrobenthos community of restored K. obovata forest reaches similar development to a normally planted $K$. obovata forest about 15 years after it has been planted. These findings indicate that ecological restoration of S. alterniflora using $K$. obovata mangrove can play a certain role in restoring benthic habitats in a region that is beyond the natural northern limit of mangrove in China. However, further investigation should be conducted to determine whether other ecosystem features (e.g., sediment property, water quality, trophic structure, etc.) would be restored. Finally, this paper emphasizes that an exotic species used for ecological restoration must have demonstrated safety and harmlessness for native habitats.

Author Contributions: J.W., C.D., Q.W. and L.S. designed the research. J.W., Q.W. and L.S. collected and processed the corresponding data. Q.W. wrote the first draft of the manuscript. C.D., S.A., G.C. and J.W. helped to organize the manuscript and edited the final version. All authors have read and agreed to the published version of the manuscript.

Funding: This research was funded by National Key Research and Development Program of China (2017YFC1405402) and Fundamental Research Funds for the Zhejiang Provincial Universities (2021XZZX012).

Institutional Review Board Statement: Not applicable.

Informed Consent Statement: Not applicable.

Data Availability Statement: Data related to this paper are available on request from the corresponding author. 
Acknowledgments: We are grateful to Hein Zar Htwe, Nuttiga Hempattarasuwan and Min Luo for assistance with field work. We also thank for researcher Hangjun Wang and Yibo Liao for species identification of macrobenthos.

Conflicts of Interest: The authors declare no conflict of interest.

\section{References}

1. Simberloff, D.; Martin, J.L.; Genovesi, P.; Maris, V.; Wardle, D.A.; Aronson, J.; Courchamp, F.; Galil, B.; García-Berthou, E.; Pascal, M.; et al. Impacts of Biological Invasions: What's What and the Way Forward. Trends Ecol. Evol. 2013, 28, 58-66. [CrossRef]

2. Chen, L.Z. Invasive Plants in Coastal Wetlands: Patterns and Mechanisms. In Wetlands: Ecosystem Services, Restoration and Wise Use; An, S., Verhoeven, A., Eds.; Ecological Studies; Springer International Publishing: Cham, Switzerland, 2019; Volume 238, pp. 97-128.

3. Lee, S.Y.; Khim, J. Hard Science Is Essential to Restoring Soft-Sediment Intertidal Habitats in Burgeoning East Asia. Chemosphere 2017, 168, 765-776. [CrossRef] [PubMed]

4. Wan, S.; Qin, P.; Liu, J.; Zhou, H. The Positive and Negative Effects of Exotic Spartina alterniflora in China. Ecol. Eng. 2009, 35, 444-452. [CrossRef]

5. Levin, L.A.; Neira, C.; Grosholz, E.D. Invasive Cordgrass Modifies Wetland Trophic Function. Ecology 2006, 87, 419-432. [CrossRef]

6. Neira, C.; Levin, L.A.; Grosholz, E.D. Benthic Macrofaunal Communities of Three Sites in San Francisco Bay Invaded by Hybrid Spartina, with Comparison to Uninvaded Habitats. Mar. Ecol. Prog. 2005, 292, 111-126. [CrossRef]

7. Qiao, P.Y.; Wang, A.D.; Xie, B.H.; Wang, L.; Han, G.X.; Zhang, X.T. Effects of herbicides on invasive Spartina alterniflora in the Yellow River Delta. Acta Ecol. Sin. 2019, 39, 5627-5634.

8. Gu, Y.F. Technologies and Their Effects on Ecological Control of Spartina alterniflora in Chongming Dongtan. J. Shanghai Jiaotong Univ. 2019, 037, 83-88.

9. Zhao, X.J.; Liu, X.Y.; Gong, L.; Deng, Z.Z.; Bai, J.D.; Li, J.S.; Zhao, C.Y. Control of Spartina alterniflora by Integrated Technique of Mowing plus Shading. Chin. J. Ecol. 2014, 33, 2714-2719.

10. Chen, B.B.; Liu, C.E.; Yuan, Y. Harm and Control Measures of Spartina alterniflora Based on Bibliometrics. Acta Agric. Shanghai 2020, 36, 90-95.

11. An, S.Q.; Gu, B.H.; Zhou, C.F.; Wang, Z.S.; Deng, Z.F.; Zhi, Y.B.; Li, H.L.; Chen, L.; Yu, D.H.; Liu, Y.H. Spartina Invasion in China: Implications for Invasive Species Management and Future Research. Weed Res. 2007, 47, 183-191. [CrossRef]

12. Grevstad, F.S.; Wecker, M.S.; Strong, D.R. Biological Control of Spartina. In Proceedings of the Third International Conference on Invasive Spartina, San Francisco, CA, USA, 8-9 November 2004. Chapter 4: Spartina Control and Management.

13. Zhou, T.; Liu, S.; Feng, Z.; Liu, G.; Gan, Q.; Peng, S. Use of Exotic Plants to Control Spartina alterniflora Invasion and Promote Mangrove Restoration. Sci. Rep. 2015, 5, 12980. [CrossRef] [PubMed]

14. Feng, J.X.; Guo, J.; Huang, Q.; Jiang, J.; Huang, G.; Yang, Z.; Lin, G. Changes in the Community Structure and Diet of Benthic Macrofauna in Invasive Spartina alterniflora Wetlands Following Restoration with Native Mangroves. Wetlands 2014, 34, 673-683. [CrossRef]

15. Feng, J.X.; Huang, Q.; Chen, H.; Guo, J.; Lin, G. Restoration of Native Mangrove Wetlands Can Reverse Diet Shifts of Benthic Macrofauna Caused by Invasive Cordgrass. J. Appl. Ecol. 2018, 55, 905-916. [CrossRef]

16. Chen, L.Z.; Wang, W.; Zhang, Y.; Lin, G. Recent Progresses in Mangrove Conservation, Restoration and Research in China. J. Plant Ecol. 2009, 2, 45-54. [CrossRef]

17. Li, M.S.; Lee, S.Y. Mangroves of China: A Brief Review. For. Ecol. Manag. 1997, 96, 241-259. [CrossRef]

18. Huang, X.L.; Peng, X.; Qiu, J.B.; Chen, S.B. Mangrove Status and Development Prospects in Southern Zhejiang Province. J. Zhejiang For. Coll. 2009, 26, 427-433.

19. Chen, S.B.; Lu, C.Y. Northward Introduction Ecology of Mangrove Plants in Response to Climate Change; China Ocean Press: Beijing, China, 2012.

20. Kristensen, E. Mangrove Crabs as Ecosystem Engineers; with Emphasis on Sediment Processes. J. Sea Res. $2008,59,30-43$. [CrossRef]

21. Lee, S.Y. Mangrove Macrobenthos: Assemblages, Services, and Linkages. J. Sea Res. 2008, 59, 16-29. [CrossRef]

22. Zhu, Z.C.; Cozzoli, F.; Chu, N.Y.; Salvador, M.; Ysebaert, T.; Zhang, L.Q.; Herman, M.J.; Bouma, T.J. Interactive Effects between Physical Forces and Ecosystem Engineers on Seed Burial: A Case Study Using Spartina anglica. Oikos 2016, 125, 98-106. [CrossRef]

23. Macintosh, D.J.; Ashton, E.C.; Havanon, S. Mangrove Rehabilitation and Intertidal Biodiversity: A Study in the Ranong Mangrove Ecosystem, Thailand. Estuar. Coast. Shelf Sci. 2002, 55, 331-345. [CrossRef]

24. Borja, A.; Franco, J.; Perez, V. A Marine Biotic Index to Establish the Ecological Quality of Soft-Bottom Benthos within European Estuarine and Coastal Environments. Mar. Pollut. Bull. 2000, 40, 1100-1114. [CrossRef]

25. Hu, C.Y.; Shui, Y.Y.; Tian, K.; Zhang, C.C.; Yi, M.M.; Shui, B.N. Community Diversity of Macrobenthos in Different Habitats of Shupaisha Wetland in Oujiang River Estuary. Oceanol. Limnol. Sin. 2016, 47, 133-139.

26. Lin, Q.L.; Gu, X.X.; Guo, X.D.; Cai, L.Z.; Lin, L. Coastal Wetland Restoration Based on Mangrove Kandelia Obovata Substitution Controlling Spartina Alterniflora Invasion: A Case Study of Aojiang Estuary in Zhejiang Province. Chin. J. Ecol. 2020, 39, 1761-1768. 
27. Yan, J.; Sui, J.; Xu, Y.; Li, X.; Wang, H.; Zhang, B. Major Environmental Variables Related to North-South Differences in the Macrozoobenthic Community in Adjacent Sea Areas of the Yangtze River Estuary, China. Ecol. Indic. 2019, 105, 70-81. [CrossRef]

28. Anderson, M.J.; Gorley, R.N.; Clarke, K.R. Guide to Software and Statistical Methods. 2016. Available online: http://updates. primer-e.com/primer7/manuals/PERMANOVA+_manual.pdf (accessed on 21 July 2021).

29. Clarke, R.; Gorley, R. PRIMER Version 7: User Manual/Tutorial 2015. Available online: http:/ /updates.primer-e.com/primer7 /manuals/User_manual_v7a.pdf (accessed on 21 July 2021).

30. Borja, A.; Tunberg, B.G. Assessing Benthic Health in Stressed Subtropical Estuaries, Eastern Florida, USA Using AMBI and M-AMBI. Ecol. Indic. 2011, 11, 295-303. [CrossRef]

31. Cai, W.; Meng, W.; Zhu, Y.; Zhou, J.; Liu, L. Assessing Benthic Ecological Status in Stressed Liaodong Bay (China) with AMBI and M-AMBI. Chin. J. Ocean. Limnol. 2013, 31, 482-492. [CrossRef]

32. Luo, X.; Zhang, J.; Yang, J.; Song, W.; Cui, W. Assessing the Benthic Habitat Quality in the Huanghe (Yellow River) Estuary and Its Adjacent Areas Using AMBI and M-AMBI. Acta Oceanol. Sin. 2014, 33, 117-124. [CrossRef]

33. Satheeshkumar, P.; Khan, A.B. Influence of Environmental Parameters on the Distribution and Diversity of Molluscan Composition in Pondicherry Mangroves, Southeast Coast of India. Ocean Sci. J. 2012, 47, 61-71. [CrossRef]

34. Hajializadeh, P.; Safaie, M.; Naderloo, R.; Shojaei, M.G.; Gammal, J.; Villnäs, A.; Norkko, A. Species Composition and Functional Traits of Macrofauna in Different Mangrove Habitats in the Persian Gulf. Front. Mar. Sci. 2020, 7, 575480. [CrossRef]

35. Lana, C.; Guiss, C. Influence of Spartina Alterniflora on Structure and Temporal Variability of Macrobenthic Associations in a Tidal Flat of Paranagua Bay (Southeastern Brazil). Mar. Ecol. Prog. Ser. 1991, 73, 231-244. [CrossRef]

36. Sueiro, M.C.; Bortolus, A.; Schwindt, E. The Role of the Physical Structure of Spartina densiflora Brong. in Structuring Macroinvertebrate Assemblages. Aquat. Ecol. 2012, 46, 25-36. [CrossRef]

37. Tang, M.; Kristensen, E. Associations between Macrobenthos and Invasive Cordgrass, Spartina anglica, in the Danish Wadden Sea. Helgol. Mar. Res. 2010, 64, 321-329. [CrossRef]

38. Chen, Q.; Jian, S.; Ma, K.; Chen, P. Differences in Macrobenthic Faunal Communities in Mangrove Wetland Habitats (Zhanjiang, China) Invaded and Non-Invaded by Exotic Cordgrass Spartina alterniflora. Ecol. Res. 2018, 33, 1113-1123. [CrossRef]

39. Braga, C.F.; Beasley, C.R.; Isaac, V.J. Effects of Plant Cover on the Macrofauna of Spartina Marshes in Northern Brazil. Braz. Arch Biol. Technol. 2009, 52, 1409-1420. [CrossRef]

40. Lana, P.C.; Couto, E.C.G.; Almeida, M.V.O. Polychaete Distribution and Abundance in Intertidal Flats of Paranaguá Bay (SE Brazil). Bull. Mar. Sci. Miami 1997, 60, 433-442.

41. Metcalfe, K.N.; Glasby, C.J. Diversity of Polychaeta (Annelida) and Other Worm Taxa in Mangrove Habitats of Darwin Harbour Northern Australia. J. Sea Res. 2008, 59, 70-82. [CrossRef]

42. Koo, B.J.; Kwon, K.K.; Hyun, J.-H. The Sediment-Water Interface Increment Due to the Complex Burrows of Macrofauna in a Tidal Flat. Ocean Sci. J. 2005, 40, 221-227. [CrossRef]

43. Wang, M.; Gao, X.; Wang, W. Differences in Burrow Morphology of Crabs between Spartina alterniflora Marsh and Mangrove Habitats. Ecol. Eng. 2014, 69, 213-219. [CrossRef]

44. Morrisey, D.J.; Skilleter, G.A.; Ellis, J.I.; Burns, B.R.; Kemp, C.E.; Burt, K. Differences in Benthic Fauna and Sediment among Mangrove (Avicennia marina Var. Australasica) Stands of Different Ages in New Zealand. Estuar. Coast. Shelf Sci. 2003, 56, 581-592. [CrossRef]

45. Dunn, G. Chloride and Osmotic Balance in the Euryhaline Sipunculid Phascolosoma Arcuatum from a Malaysian Mangrove Swamp. Biol. Bull. 1976, 150, 211-221.

46. Ip, Y.K.; Tan, G.Q.; Kuah, S.S.L.; Chew, S.F. Detoxification of Environmental Sulfide to Sulfane Sulfur in the Intertidal Sipunculid Phascolosoma Arcuatum. J. Comp. Physiol. B Biochem. Syst. Environ. Physiol. 1997, 167, 213-220. [CrossRef]

47. Liao, Y.; Shou, L.; Tang, Y.; Gao, A.; Chen, Q.; Yan, X.; Chen, J. Influence of Two Non-Indigenous Plants on Intertidal Macrobenthic Communities in Ximen Island Special Marine Protected Area, China. Ecol. Eng. 2018, 112, 96-104. [CrossRef]

48. Chen, Q. Changes in the Macrobenthic Faunal Community during Succession of a Mangrove Forest at Zhanjiang, South China. J. Coast. Res. 2015, 31, 315-325. [CrossRef]

49. Li, Y.F.; Du, F.Y.; Gu, Y.G.; Ning, J.J.; Wang, L.G. Changes of the Macrobenthic Faunal Community with Stand Age of a Non-Native Mangrove Species in Futian Mangrove National Nature Reserve, Guangdong, China. Zool. Stud. 2017, 56, e19. [PubMed]

50. Kon, K.; Kurokura, H.; Tongnunui, P. Effects of the Physical Structure of Mangrove Vegetation on a Benthic Faunal Community. J. Exp. Mar. Biol. Ecol. 2010, 383, 171-180. [CrossRef]

51. Liao, Y.; Shou, L.; Tang, Y.; Zeng, J.; Chen, Q.; Yan, X. Effects of Non-Indigenous Plants on Food Sources of Intertidal Macrobenthos in Yueqing Bay, China: Combining Stable Isotope and Fatty Acid Analyses. Estuar. Coast. Shelf Sci. 2020, 241, 106801. [CrossRef]

52. Kon, K.; Kurokura, H.; Hayashizaki, K. Role of Microhabitats in Food Webs of Benthic Communities in a Mangrove Forest. Mar. Ecol. Prog. Ser. 2007, 340, 55-62. [CrossRef]

53. Chen, G.C.; Ye, Y. Restoration of Aegiceras Corniculatum Mangroves in Jiulongjiang Estuary Changed Macro-Benthic Faunal Community. Ecol. Eng. 2011, 37, 224-228. [CrossRef]

54. Chen, G.C.; Ye, Y.; Lu, C. Changes of Macro-Benthic Faunal Community with Stand Age of Rehabilitated Kandelia Candel Mangrove in Jiulongjiang Estuary, China. Ecol. Eng. 2007, 31, 215-224. [CrossRef]

55. Nobbs, M. Effects of Vegetation Differ among Three Species of Fiddler Crabs (Uca spp.). J. Exp. Mar. Biol. Ecol. 2003, 284, 41-50. [CrossRef] 
56. Xiang, H.; Li, K.; Cao, L.; Zhang, Z.; Yang, H. Impacts of Pollution, Sex, and Tide on the Time Allocations to Behaviours of Uca Arcuata in Mangroves. Sci. Total Environ. 2020, 742, 140609. [CrossRef] [PubMed]

57. Chen, G.C.; Gao, M.; Pang, B.; Chen, S.; Ye, Y. Top-Meter Soil Organic Carbon Stocks and Sources in Restored Mangrove Forests of Different Ages. For. Ecol. Manag. 2018, 422, 87-94. [CrossRef]

58. Feng, J.X.; Zhou, J.; Wang, L.; Cui, X.; Ning, C.; Wu, H.; Zhu, X.; Lin, G.H. Effects of Short-Term Invasion of Spartina alterniflora and the Subsequent Restoration of Native Mangroves on the Soil Organic Carbon, Nitrogen and Phosphorus Stock. Chemosphere 2017, 184, 774-783. [CrossRef] [PubMed]

59. Chen, H.; Liao, B.; Liu, B.; Peng, C.; Zhang, Y.; Guan, W.; Zhu, Q.; Yang, G. Eradicating Invasive Spartina alterniflora with Alien Sonneratia apetala and Its Implications for Invasion Controls. Ecol. Eng. 2014, 73, 367-372. [CrossRef]

60. Ashton, E.C.; Macintosh, D.J.; Hogarth, P.J. A Baseline Study of the Diversity and Community Ecology of Crab and Molluscan Macrofauna in the Sematan Mangrove Forest, Sarawak, Malaysia. J. Trop. Ecol. 2003, 19, 127-142. [CrossRef]

61. Hu, C.Y.; Shui, B.N.; Li, W.; Yang, X.; Zhang, X. Assessing the Ecological Quality Status of Transplanted Mangrove Wetland in the Oujiang Estuary, China. Mar. Pollut. Bull. 2018, 133, 1-8. [CrossRef] 